\title{
A ORDEM ASTRAL: A AÇÃO DO PRINCEPS OTÁVIO AUGUSTO PELA LEGITIMIDADE DO SEU PODER
}

\author{
Profa. Dra. Ana Teresa Marques Gonçalves ${ }^{1}$ \\ Prof. Doutorando Rodrigo Santos M. Oliveira ${ }^{2}$
}

\begin{abstract}
Resumo: Voltamos o nosso olhar para as relações políticas durante o Principado romano em uma tentativa de compreender nossas experiências do presente. Assim agindo, percebemos que líderes romanos já articulavam suas ideias perante um vasto e heterogêneo público. Sendo assim, propagar uma boa imagem não seria uma necessidade apenas para o princeps (ou atual): Senado, povo de Roma e províncias precisavam adotar certas posturas a fim de obterem, também, benefícios. Um jogo de poder era estabelecido, e para entendê-lo, destacamos o governo de Otávio Augusto. Analisamos tal período, pois representa uma ruptura entre dois momentos da História romana (República e Principado), ao mesmo tempo em que este líder promoveu, ao considerarmos suas posturas e discursos, uma continuidade de elementos tradicionais republicanos. Ou seja, o discurso aludia à sua prática, e convencia os demais de sua legitimidade. Em busca de ordenamento, Marco Manílio, autor de Astronomicas, acabou por nos proporcionar novas ferramentas para a realização desta análise; até os astros explicam os poderes atribuídos à Otávio, ao Senado e ao povo romano.
\end{abstract}

Palavras-Chave: Propaganda; Poder; Astrologia; Otávio Augusto.

\section{INTRODUÇÃo}

Horários eleitorais, folhetins informativos durante campanhas, comerciais televisivos, entre outros recursos, são utilizados atualmente para "informar" o eleitor a respeito dos candidatos que pretendem ocupar qualquer cargo de chefia no governo. Tal propaganda se faz necessária, pois através desta ocorre a aproximação - mesmo que em um plano abstrato e não físico - entre os que votam e os votados. Atualmente, em nosso sistema democrático, temos a ideia de que os governantes são escolhidos a partir do voto e pelo povo que

\footnotetext{
1 Professora Associada 4 de História Antiga e Medieval na UFG. Doutora em História pela USP. Bolsista Produtividade II do CNPq. Contato: anateresamarquesgoncalves@gmail.com

${ }^{2}$ Doutorando pelo Programa de Pós-Graduação em História - UFG, bolsista CAPES, orientado pela Profa. Dra. Ana Teresa M. Gonçalves. Contato: rodrigo.sm.oliveira@gmail.com.
} 
se identifica com as propostas elencadas pelo aspirante a ocupar um cargo do governo. Devido às diferenças percebidas no período histórico conhecido como Principado romano, pensou-se, por muito tempo, que a propagação de ideias e imagens não fosse necessária para escolha e legitimação do Princeps. O líder seria escolhido entre um membro da elite romana (especificamente, do grupo senatorial), e por esta governaria, sem precisar realizar o que chamamos hoje de "prestação de contas". O poder deste líder seria absoluto e apenas terminaria em ocasião de morte ou de sucessão. Porém, ao nos atentarmos aos estudos recentes sobre a ação do Princeps, percebemos que este desempenhava um papel de maior elasticidade e dependência em relação aos seus subordinados. Ele também necessitava aprender a "dançar conforme a música", e não simplesmente ditar regras e ser temido.

Sendo assim, o presente trabalho visa compreender melhor tais relaçóes durante o Principado romano, especificamente nos centrando na figura de Otávio Augusto. A principal documentação utilizada é a obra de Marco Manílio, Astronomicas (século I d.C.), na tentativa de entender, a partir de uma fonte não usual para se explicar o panorama político, como tais representações do líder romano eram importantes para a consolidação e legitimação de seu governo, e, ainda, como poderiam ser realizadas. Os astros, signos e porções celestes influenciaram as ações dos seres humanos, servindo para legitimá-las ou negá-las.

\section{I - O PRINCEPS: UM PANORAMA GERAL}

Como aponta Louise Revell (2009, p.80), o Princeps seria uma abstração, pois representava mais que um indivíduo em exercício de uma magistratura: "a habilidade de indivíduos específicos pode ser desafiada, mas não a figura do Imperador como detentor da autoridade política". Sendo assim, o Imperador era aquele que, além de possuir a magistratura, desempenhava um papel de autoridade, ou seja, um status superior verificado em um plano ideológico e não prático/legal. O poder que exercia se mantinha e se legitimava a partir das magistraturas que agregava ou negava, assim como fez Otávio. A repetição com que ganhava tais cargos mostrava a autoridade e o controle que cada Princeps possuía.

Temos que nos atentar ao fato de que nem todos os líderes possuíam os mesmos cargos e se destacavam da mesma forma. Vide o exemplo de Otávio e de Tibério (linha sucessória): ambos se utilizaram de mecanismos similares para atingir seus objetivos perante o Senado e o povo de Roma; porém, enquanto o primeiro foi tido como humilde e legitimamente possuidor da 
honra necessária para governar, o segundo foi tachado como exemplo de falsa modéstia e um líder ruim. (SUETÔNIO, Vida de Tibério, v. 28-35)

São inúmeras as hipóteses, generalizações e estereótipos construídos. Um desses, deveras difundido entre historiadores da Antiguidade, é o apresentado por Paul Veyne (2009). Em seu livro, O Império Greco-Romano, este autor elege como melhor forma de representação de um Imperador um modelo bem curioso ${ }^{3}$ :

Quem era o Imperador romano? Um aventureiro bem sucedido ou cujo pai obtivera sorte; a dignidade imperial não estava, então, ancorada ao grave rochedo da propriedade patrimonial que atravessa os séculos (VEYNE, 2009, p. 4).

Tal imagem não satisfaz nossa necessidade de construção da figura imperial. O Princeps, a partir desta análise, é quase um inconsequente, um acaso, sendo altamente dependente da indicação e dos bens do seu pai para poder sobreviver e possuir a legitimação necessária. Vínculos com ancestrais importantes não eram suficientes para manter alguém no comando. Utilizandonos novamente do exemplo de Tibério, mesmo que se associando a Otávio, sua imagem não se manteve favorável perante o Senado romano. Mesmo assim, afirmamos que a associação entre o Princeps e seus antepassados era uma poderosa arma de poder. Apenas salientamos que não seria exclusivamente isto a confirmar um governo.

Mesmo que claramente, para nós historiadores, tenha sido instituído um novo modelo político a partir de Otávio, denominado como Principado, percebemos que o romano, contemporâneo ao evento, não foi sensível a tal mudança. Ainda nos espelhando na figura deste líder, sabemos que ao assumir as magistraturas e ter o reconhecimento do Senado, Otávio não inaugurou um novo modelo político, ao contrário:

Quando Augusto ganhou supremo poder como Princeps, ele colocou o sistema político romano em um caminho que não se desviou para a duração do Império: enquanto a retórica de um retorno para a

3 "O príncipe, na verdade, é todo-poderoso. Seu poder é o mais absoluto, completo e ilimitado possível; não é compartilhado com ninguém, assim como a ninguém ele deve prestar contas. Apenas restrições auto-impostas limitam tamanha onipotência. A razão estava na concepção romana de poder, do imperium, o poder absoluto e completo (o mesmo de um oficial no campo de batalha, detentor do direito de vida e de morte sobre seus homens, em que desobediência e delito não se distinguem); no Império, esse poder é depositado nas mãos de um único homem, em vez de ser dividido entre diversos magistrados [...] Contudo, como príncipe, tem o poder de decidir a paz e a guerra, aumentar os impostos e incorrer nas despesas que quiser; nada lhe escapa (é o senhor dos cultos públicos e do direito pontifício) e nenhum poder limita o seu" (VEYNE, 2009, p. 9). 
democracia da República aparecia nos textos da elite, os eventos históricos demonstravam que esta não era mais uma alternativa viável (REVELL, 2009, p. 80).

Assim como apresenta Geoffrey Sumi (2005, p. 221), ao assumir seu posto, Otávio se declarou como restaurador da República, consolidando seu papel como Princeps. Ele se utilizava de valores republicanos para criar uma "nova forma" de governo: "Augusto adapta os requerimentos da tradição e dos valores da República romana para sua própria necessidade e autopreservação política e dinâmica".

Otávio iniciou sua campanha ainda durante o período do triunvirato. O período citado foi de grande conturbação na organização e manutenção da República romana. Roma, especificamente a cidade, vivia um período de desestabilidade interna agravada pela disputa constante entre grupos de elevadas camadas. Otávio e Marco Antônio iniciaram um confronto que mexeu com a estrutura política romana, modificando o espaço sócio-político da República para o que nós, historiadores, chamamos de Principado. Tal mudança não foi sentida e confirmada pelos próprios romanos deste período. Mesmo após a vitória, Otávio não inaugurou outra ordem, ou se proclamou líder soberano. O que este líder fez foi conquistar a Pax Romana - não absoluta - e devolver o poder ao Senado e povo de Roma, sendo assim, reconhecido como o grande restaurador da República.

Em sua estratégia contra Marco Antônio, Otávio se apresentou como protetor e mantenedor da tradição, associando-se aos costumes romanos e ao deus Apolo. Enquanto isto, ele destacava em seus discursos as preferências de Antônio pelo Oriente, a associação deste com uma divindade estrangeira, Dionísio, e sua relação adúltera com Cleópatra. Dessa forma, M. Antônio fere o que John A. Lobur (2008, p. 15) nomeia de "sensibilidade romana".

Baseando-nos nos relatos de Suetônio, foi gerado, em todas as camadas sociais de Roma, um consensus pertinente à imagem de M. Antônio como inimigo da República, devido sua postura diante dos "prazeres orientais", o que acabou por comprometer toda a autoridade que este possuía. Enquanto isto, Otávio tomou o caminho contrário ao do seu rival: através de discursos e rituais diante de todos os cidadãos, expressou sua vontade de restaurar a República revivendo as tradições. Otávio realizou isto para que a opinião pública (que acabara com seu rival) estivesse ao seu lado, gerando consensus acerca de sua boa liderança. Sua campanha foi tamanha que ainda proclamou "Roma livre do medo". 
"A visível manifestação deste 'consensus', descrito, claramente existente nas fontes é elevado ao nível de mitologia" (LOBUR, 2008, p.27). A imagem de Otávio começa a ser cunhada como herói mitológico fundador de Roma, o que demonstra o poder que exercia perante toda a sociedade. No escudo de Enéias (descrito por Virgílio) havia a mensagem "Liderando os italianos na batalha, juntamente com o Senado e o povo", demonstrando que Otávio adquirira consensus no que tange seu poder em Roma ${ }^{4}$. Além disso, este líder modificou a topografia da cidade, alegando que assim restauraria a República. Após a batalha de Áccio, ele reformou o fórum de César que, juntamente com a Cúria, simbolizava a República em si a partir da imagem essencial do Senado.

Mas o que seria esse consensus? Não possuímos a pretensão em acreditar que este seria total e absoluto, e sim, se basearia em uma grande aprovação diante da figura imperial. O texto de Clifford Ando (2000) trabalha com este conceito que, para nós historiadores da contemporaneidade, é difícil de compreender. Tal termo é empregado no período do Principado Romano a fim de facilitar a apreensão do exercício de poder nesta sociedade, representado pelo Princeps, Senado e províncias. Tal consensus, por mais que instituído e idealizado como universal, sempre foi a chave para se entender a relação existente entre estes três estamentos fundamentais para a manutenção do que seria o Império Romano. Percebemos, então, que nenhum grupo ou indivíduo detinha em si poder - enquanto controle - total. Era necessário articular ideias, conquistar aliados e, com isso, gerar consensus. Este não seria algo dado e, muito menos, intrínseco a alguém: deveria ser conquistado, legitimado e cultivado para que existisse. Assim, ter consensus seria mais uma ferramenta de propaganda do que uma certeza de legitimidade:

Documentos que invocam tal consensus raramente clamam por representar a visão de todo o mundo; ao invés disso, eles pretendiam representar a visão de grupos particulares. Ao fazer isso, estes documentos criavam clivagens dentro da população geral, dividia lealdades, e permitia a expressão de certa unidade somente quando expressavam (os Imperadores) o compromisso com o estabelecimento da ordem (ANDO, 2000, p. 135).

O consensus, assim como afirma o autor supracitado, mostrava o limite entre o poder real do Princeps e seu carisma. Desta maneira, temos uma ideia

4 Sabemos que este consensus não era absoluto, por mais universal que tente ser. Temos isso em mente pelo fato das incessantes demonstraçóes de Otávio como um excelente líder e restaurador da República. Partimos do pressuposto de que se tal consensus fosse realmente aceito e não questionado por todos, não haveria a necessidade de tal afirmação constante do poder augustano. 
de unidade política e geográfica que se baseia em uma relação comum entre os liderados e seu líder, e se opera a partir da língua compartilhada e da cidadania concedida. O Princeps assumia seu papel em reluta, afirmando que exercia suas funções em nome e pelas causas da República, mostrando que todos estavam submetidos às leis: ele tinha como prioridade em suas preocupações o bem público, ou pelo menos essa era a ideia que se esforçava para passar. Voltandonos ao exemplo de Otávio, mesmo obtendo inúmeros títulos e crescente poder, ele não se opôs ao Senado dentro de sua política. Ao contrário: reconhecer a autoridade do Senado era reconhecer a própria autoridade (autoridade do Princeps, neste caso), já que este era escolhido por aquele grupo. Utilizar quiçá manobrar - o Senado conforme sua vontade era a primeira lição que um bom Princeps deveria aprender. Otávio se tornou parceiro do Senado e estabeleceu, com isso, sua autoridade. Ele entregava o poder e autoridade ao próprio povo de Roma e ao Senado, diferentemente do que fez César ao reivindicar tal poder para si.

Assim como pontuado por Geoffrey Sumi (2005), Otávio criou cerimônias públicas para manter-se no poder, enquanto César não o fez: o segundo era ditador, cargo passageiro e talvez, por isso, não se preocupou com tais cerimônias. $\mathrm{O}$ primeiro Imperador foi um grande adaptador e não um inovador. Ao abrir mão da ditadura, ele se afastou do deslize de César e, a partir dessa negação, acabou por aumentar seu próprio prestígio.

A oratória era de extrema importância para um bom líder. Otávio reformou o fórum e mostrou a importância de um bom discurso: ele dá voz aos tribunos não apenas para dividir o poder, mas, também, para ter alguém que lhe elogie publicamente; seu discurso dava voz aos outros, ou seja, não discursava sozinho, não apresentava as benesses que fizera sozinho e, dessa maneira, aumentava seu próprio poder.

Com o início do Principado de Otávio as relações entre periferia e centro mudaram. Este se mostrava como filho e herdeiro de César, fazendo dos clientes do pai seus próprios clientes. De acordo com Clifford Ando, a maior conquista augustana foi concebida a partir de seu carisma - este, associado à universalização de seus clientes - e à divinação de César, que apresentamno como o líder legítimo. Otávio buscava ter auctoritas, percorrendo todo o processo elencado por J.E. Lendon (2005): buscou a honra ao expressar suas virtudes, recebendo a dignitas capaz de lhe conceder a fama, ou seja, uma imagem positiva. Não buscou a honra coercitiva, pois ela é passageira e não se mantém para os seus sucessores, preferindo também realizar constantemente cerimônias que aumentassem seu prestígio do que esbanjar simplesmente as riquezas advindas da Fortuna (estas, de acordo com Lendon, seriam passageiras). 


\section{2 - Consolidação da imagem Imperial: Otávio Augusto e SEUS VASTOS RECURSOS}

Otávio se utilizou de inúmeros recursos para propagar uma boa imagem e se manter no poder. Desde sua postura perante o Senado - já abordada no tópico acima -, até em como se fazia representar, Otávio Augusto foi um Imperador capaz de atingir certo consensus perante seus liderados.

Em sua trajetória, Augusto mostrou que não foi o agente que conquistou sozinho o poder. $\mathrm{Na}$ verdade, o Senado entregou este poder a ele, pois reconheceu suas virtudes. Ele apenas devolveu tal poder ao povo e ao Senado e conquistou, desta forma, maior consensus (ele se mostrou como o restaurador da República). Um bom líder, de acordo com Clifford Ando, deveria recusar o poder. Augusto, a partir de tal lógica, chegou a receber o título de Pai da Pátria.

Como afirma Marco Manílio, Astronomicas, até mesmo os astros confirmam o poder de Augusto 5 . Nos livros I, II e III, a exaltação ao signo de Capricórnio - signo de nascimento do Princeps Otávio Augusto - é averiguada:

Também não são inferiores quanto ao resto: são dominados por um único astro, Augusto, estrela que por sorte coube ao nosso orbe, o maior legislador agora na terra, depois no céu (MANíLIO, Astronomicas, Livro I, v. 473-478).

[...]

Capricórnio, ao contrário, dirige seu olhar para si mesmo (qual outro, em efeito, poderia admirar mais importante, se foi ele quem brilhou com tão bom presságio no nascimento de Augusto) (MANíliO, Astronomicas, Livro II, v. 507-509).

A partir de tais excertos da obra, podemos definir que os três primeiros livros foram escritos durante o Principado de Augusto. A expressão "o maior legislador agora na terra", utilizada no Livro I, designa que este Imperador se encontrava vivo naquele período, e a exaltação de seu signo se torna uma "propaganda"6 inerente à legitimação do poder imperial, já que apresenta

5 Tal relação entre Céu e Terra é o elemento chave da obra maniliana. Manílio determina e mostra ao leitor o quão interligados estão estes dois espaços, sendo a vida terrena uma projeção dos acontecimentos celestes. Esta unidade universal recebe o nome de "simpatia universal", a qual, todos, de acordo com os estoicos, estavam condicionados. Desde as estrelas até a menor das plantas, todo o Universo estava unido pela criação do deus que o concebeu.

6 “[...] o simples, mas importante, ato de organizar, selecionar e divulgar informações, usando de persuasão, síntese e de imagens que estão na memória dos receptores das mensagens" (GONÇALVES, 2002, p. 74). 
Otávio como o líder, não só de Roma, mas de todo o mundo, escolhido pelos astros.

Manílio atribui inúmeras referências a Augusto e ao seu poder, legitimando-o:

A mim, ó César ${ }^{7}$, da pátria primeiro homem e pai, tu que reges o mundo submisso às tuas augustas leis e que mereces, tu próprio como um deus, o céu concedido antes a teu pai $^{8}$, me inspiras e fortaleces para cantar tamanhas coisas (MANÍLIO, Astronomicas, Livro I, v. 8-12). $[\ldots]$

Para eles (povos que vivem abaixo da linha do eixo, ou seja, extremidade inferior do globo) o céu não é menor nem pior em luz, nem menos numerosas nascem as constelações em seu orbe. Também não são inferiores quanto ao resto: são dominados por um único astro, Augusto, estrela que por sorte coube ao nosso orbe, o maior legislador agora na terra, depois no céu (MANÍLIO, Astronomicas, Livro I, v. 473-479).

[...]

[...] e a raça Júlia, descendente de Vênus. Augusto desceu do céu e o céu ocupará, o qual irá reger [...] (MANíLIO, Astronomicas, Livro I).

Como podemos perceber, até mesmo os astros cooperam para a legitimação da imagem de Augusto como o Princeps. Porém, esta não foi a única forma que este encontrou para legitimar sua ação. São inúmeros os métodos e mecanismos utilizados por Augusto que apresentavam-no virtuoso o bastante para possuir a autoridade necessária e, dessa forma, se destacar dos demais.

Um dos meios mais utilizados para a propagação de seus ideais foi a literatura. A própria obra maniliana nos é um bom exemplo disto. Mesmo que elaborando um manual do conhecimento astrológico, Manílio afirma que sua produção é um poema sobre a beleza do Universo; ele cria sua narrativa como uma literatura. Sua intenção não era somente passar um conhecimento científico do que seria o universo e as relações e distâncias dos corpos celestes, mas também criar uma narrativa que fosse digna da beleza dos astros. $\mathrm{O}$ próprio autor mostra o quão laboriosa foi a realização de tal tarefa:

É fácil dar à vela com os ventos favoráveis, e revolver o solo fecundo com técnicas variadas, e ao ouro e ao marfim acrescentar ornato,

7 Augusto 
quando a rude matéria mesma já tem brilho. Escrever poemas sobre assuntos sedutores é comum, bem como compor uma obra simples. Quanto a mim, porém, tenho de lutar com números, desconhecidos nomes de coisas e frações de tempo, com as diferentes circunstâncias e movimentos do céu, e a ascensão das constelações, e com as partes nas suas próprias partes. Se conhecer essas coisas já é muito, que será então de exprimi-las? E numa poesia adequada a elas? E de submeterlas a um metro fixo? Aproxima-te, ó quem quer que sejas que possas aplicar ouvido e olhos à minha empresa, e ouve as palavras verdadeiras. Presta atenção, e não procures doces carmes: a matéria mesma recusa o ornato, satisfeita com ser ensinada. E, se alguns nomes forem referidos em língua estrangeira, culpa será do tema, não do vate: nem tudo se pode verter, designando-se melhor em sua própria língua (MANÍLIO, Astronomicas, Livro III, v. 32-52).

Mesmo em uma sociedade de maioria não letrada, a literatura desempenhava um papel importantíssimo, pois alcançava a elite romana e a persuadia. A comunicação entre o Imperador e seus súditos, fossem eles próximos ou distantes - como é o caso das províncias - era de extrema importância. Assim como pontua Richard Miles (2005, p. 29), a comunicação deve ser entendida como um processo que se apresenta a partir de um ou mais níveis. Não se pode dizer que a comunicação é simplesmente interação presencial entre duas pessoas ou mais, pois pode ser feita de maneiras verbais ou não, influenciando na criação de outras crenças e comportamentos. A comunicação se baseia, então, em dois conceitos-chave: a articulação das ideias e a sua transmissão.

Temos que nos atentar para o poder que a palavra escrita possuía: só nos chegou o que foi escrito. $\mathrm{O}$ falado sobreviveu graças à escrita. Porém, não podemos definir uma sociedade pelos letrados. A "alfabetização" não é uma ferramenta universal da cultura, mas é inseparável da educação. No Império, a palavra escrita desempenhou um papel - quase que - central: na passagem das leis, no comando dos exércitos, etc.. O Imperador tinha contato com seus subordinados, muitas das vezes, por correspondência (MILES, 2005, p. 37). Sem a palavra escrita seria impossível a manutenção do Império. $\mathrm{O}$ conhecimento era poder e o Império romano soube articular bem as informações do governante aos governados (e o inverso também): datas importantes, grande eventos de construção e astrológicos eram registrados (MILES, 2005, p. 38).

A escrita era tão importante que os Imperadores também investiam na escrita de suas autobiografias. Otávio, por exemplo, escreveu sua autobiografia para estabelecer sua imagem - serviria como uma forma de propaganda. Nela, 
mostrou a origem divina de sua família (ligada à deusa Vênus), sua ligação com o divino César e todas as glórias que conquistou e lutou por Roma como a batalha contra Marco Antônio. Através destas ligações com ancestrais importantes, e até divinos, Otávio se colocou em lugar de destaque ao se pronunciar como legitimamente escolhido entre os homens e os deuses.

Assim como apresenta Geoffrey Sumi, o Princeps se utilizava de cerimônias para se apresentar ao Senado e ao povo, tendo que suas ações serem altamente performáticas. Até mesmo após sua morte, Augusto deixou especificações claras de como deveria ser feito todo o ritual. O corpo de Otávio ficaria no templo de Divus Julio, já que este templo estava associado à divinização de César - importante pela associação desde a adoção -, e seria levado para o Campo de Marte e não para o Fórum (quebra nos protocolos, mas com razões políticas)."Três imagens de Augusto foram carregadas na procissão do funeral" (SUMI, 2005, p. 257): uma como triunvirato, outra como senador e a terceira como triunfante em uma biga. Além dessas, Augusto colocou imagens de sua família, incluindo sua ligação com César e Rômulo (além de sua associação a Enéias e a Afrodite). Ele exigiu que seu corpo passasse em uma procissão pelos monumentos que construiu e restaurou e, dessa forma, se fez lembrado.

As imagens do Imperador que eram divulgadas também eram utilizadas para legitimá-lo. Elas divulgavam, assim como pontua Louise Revell (2009), imagens que o legitimassem não somente em relação à sua posição pessoal/ individual, mas também afirmavam sua legitimidade a partir da família e de sua ligação com os deuses (como o exemplo já citado: Augusto). Não podemos ter noção de quantas pessoas viam tais imagens, porém o acúmulo dessas nos dão uma ideia da importância e do reforço que causavam. O Imperador faziase representar sempre em seu auge, ou seja, novo e belo. Fica difícil distinguir as estátuas dos Imperadores, pois os temas se repetiam demais. Um tema bastante repetido era a representação do Imperador como herói, nu, o que mostrava sua natureza super-humana.

Nos dias atuais, historiadores da arte não se preocupam apenas com a imagem, mas também com sua recepção. A estátua do Imperador poderia receber sacrifícios, e participar de processos religiosos sendo carregada - algo que acontecia durante o culto imperial. Tais estátuas eram colocadas em lugares estratégicos e públicos para que o maior número de pessoas pudesse ver e, com isso, lembrar-se do poder imperial. As estátuas expostas não eram somente do Imperador, mas também de seus familiares. Tais imagens legitimavam a autoridade do mesmo, mostrando o quão digno era o seu comando, já que descendia de uma família importante. 
Sabendo de tais veículos de propagação da imagem imperial utilizados pelo Princeps, temos que nos atentar também à divulgação de tal imagem em relação às províncias, já que o Império Romano se fez conhecido pela sua vastidão territorial. Dessa maneira, é válido nos perguntarmos "Como o Imperador mantinha o controle e propagava sua imagem para estes povos tão distantes?".

\section{3 - O IMPERAdor E SEUS LONGínQUOS SÚditos: A RELAÇÃo ENTRE ROMA E AS PROVínCIAS}

A vastidão do Império Romano é abordada em vários documentos, e o próprio Manílio nos dá uma noção de tal tamanho:

Aí (no território da África), coube a Cartago, pelas armas, o poder, no tempo em que Aníbal arrasou com fogo as fortalezas alpinas e tornou eterno o Trébia, cobriu Canas de sepulcros e fez a Líbia introduzirse nas cidades do Lácio. Em Cartago, a natureza, contrária a futuras guerras, reuniu pestes de várias espécies e uma variedade de feras monstruosas. Esta terra selvagem tem horrendas serpentes, e animais cujos membros são habitados por veneno, e seres cujo pasto é a morte, acusaçôes contra a terra, e ainda enormes elefantes têm, produzido, ainda, a selvagem terra, fértil de seu próprio castigo, cruéis leões, divertindo-se com o parto de monstruosos macacos; e, pior do que se fosse estéril, ela infesta de maus frutos suas áridas areias, até que abandona sua autoridade junto aos habitantes do Egito. A partir daí estão os povos da Ásia, e uma terra em tudo rica: correm rios de ouro, e de pérolas rebrilha o mar, perfumadas florestas sopram o aroma de plantas medicinais: A Índia, maior que o conhecimento que dela se tem, e os partos, ou (se queres) um outro mundo, e as muralhas de Tauro, que se elevam ao céu, e as tantas raças, em redor dele, com diferente nome, nações junto ao Tânais, que separa as terras com as águas cíticas, e junto ao lago Meótida e aos perigos do Ponto Euxino. Este é o limite que a natureza impôs à poderosa Ásia. O que resta é a Europa que ocupa, a primeira que recebeu Júpiter, quando nas ondas ele nadava, e que pôs o touro em liberdade [...]. Ele presenteou com o nome da menina o litoral, consagrando com tal título o monumento do amor. É, pelos seus varões, a terra mais ilustre e a mais fecunda em doutas artes: Atena, florescente no seu poder sobre a palavra; Esparta, reconhecida por sua força militar; Tebas, por seus deuses; e Péla, por um único rei, a sua morada principal, reconhecimento pela guerra troiana; Tessália, e Epiro poderosa, e a costa, vizinha, da Ilírica; e a Trácia, à qual coube a sorte de ter Marte por habitante; e a Germânia, admirada entre os seus filhos; a Gália, por suas riquezas; a Hispânia, grandiosa por suas guerras; e, acima de todas, a Itália, que Roma a 
maior de todas, impôs ao mundo, unindo-se ela mesma ao céu. Tais são os limites em que a terra e o mar devem ser examinados [...] (MANÍliO, Astronomicas, Livro IV, v. 799-841).

Foi vastíssimo o território ocupado pelo Império Romano, e agregava diversas culturas. Porém, como Roma obtinha o controle de algo tão grandioso? Andrew Wallace-Hadrill (2008) percebe na cultura a diferenciação existente no governo augustano; não existe uma cultura romana pura e nem um processo de romanização puro. A identidade romana não é dicotômica. Ela é plural e consegue sobrepor inúmeras identidades com facilidade: a romanização e a helenização não são processos excludentes, mas agregadores. O Império Romano era multilinguístico, e a cultura não era apenas imposta, ela também era absorvida. Estabelece-se, então, uma idealização cultural que se aplicava nas províncias, ou seja, o que se originava era uma liga cultural que une características romanas e provinciais. $\mathrm{O}$ exemplo romano sempre se voltava à manutenção do mos maiorum e, por isso, Wallace-Hadrill utiliza-se, para explicar tal formação cultural, do conceito de dialética cultural. A própria Itália era plural em relação às culturas existentes, e por isso o entendimento de romanização também o era: uma romanização mais pela seleção do que pela expansão.

Dessa maneira, entendemos que a identidade seria um processo de fabricação. Ser romano seria se educar romano, aprender a se portar de acordo com os interesses romanos, e não apenas reivindicar algumas divindades e/ou costumes. $\mathrm{O}$ processo de romanização não seria a mera substituição da cultura local pela romana, e sim um processo similar à uma adição. Processos como a hibridização ${ }^{9}$ ou a fusão ${ }^{10}$ cultural não explicariam a complexidade da transformação cultural existente a partir do contato entre Roma e as províncias. Estudos recentes, como o de Wallace-Hadrill (2008, p. 31), mostram que a cultura não é unilateral e nem responde simplesmente a processos civilizadores. A palavra cultura é derivada do latim cultivas que agrega a metáfora da cultivação e que realiza um paralelo com a vida humana e a natureza.

Sendo assim, para que esse diálogo cultural pudesse acontecer, as relações com as províncias deveriam ser mantidas de alguma forma, e a imagem do Imperador deveria ser propagada: e este é outro quesito que Otávio Augusto

$9 \mathrm{Na}$ hibridização, o resultado tem características dos originais, porém é estéril, ou seja, não pode produzir e propagar tal cultura.

$10 \mathrm{Na}$ fusão (como na do metal) forma-se outra coisa - cultura -, diferente das que lhe deram origem. 
buscou preencher. A primeira teoria vigente sobre estas relaçóes apresentava a percepção de dominação, em que Roma sobrepujava os povos dominados. Tal teoria se associa aos conceitos de civilização e progresso: Roma teria um papel de levar progresso e civilidade aos povos dominados. Esta ideia foi bastante utilizada durante a expansão dos Estados modernos para justificar suas ações, elegendo como exemplo maior Roma - foi construído um "discurso de dominação" ancestral que atendia aos interesses imperialistas dos países europeus frente às conquistas territoriais/econômicas (HINGLEY, 2010, p. 69). Surge também o conceito humanista, praticamente teleológico, de que Roma se apropria do legado grego e se torna o motor da civilização Ocidental.

Assim como destaca Richard Hingley (2010, p. 71), essa teoria defendia a existência de uma unidade da civilização imperial romana e a criação do conceito de romanização que enfatizava "um processo de 'progresso' desde uma cultura 'bárbara' até uma 'romana' na expansão do Império". Nessa, a periferia (províncias - povos dominados de uma maneira geral) só era percebida a partir do seu grau de civilização e aproximação com o centro político.

A partir da década de 1960, cresce o número de historiadores que se utilizam de um novo foco: não mais a unidade era o centro das discussões, mas sim a "variabilidade das respostas locais a Roma" (HINGLEY, 2010, p. 73). A cultura romana passa a ser percebida como uma cultura mais heterogênea, e tal diversidade articulava uma lógica inclusiva que "não mais formula a si mesma em torno da criação de categorias e de hierarquias” (HINGLEY, 2010, p. 79) $)^{11}$.

A heterogeneidade garantia a manutenção do Império - porém, não pensamos que isso seja obra do acaso. Não havia uma "mudança de identidade", e sim uma adaptação. Uma nova teoria surge disso: acontecia entre as culturas uma negociação e interação social na formação da identidade romana.

Alguns autores mostram uma utilização da força para divulgar a identidade romana. Porém, pensamos que não podemos creditar somente à força (militar) esse papel. O exército foi um grande propagador da romanização. As elites (romanas e provinciais) foram utilizadas para o desenvolvimento dos centros urbanos locais. Mas, outra maneira de romanizar os nativos foi a difusão do latim. As elites provinciais aprendiam o latim como uma forma de se aproximarem e tornarem-se "mais romanas", aceitando, não de maneira

11 "Isso permite perceber-se o império romano como uma sociedade mais heterogênea, em que grupos e indivíduos atuavam diferentemente para 'se tornarem romanos', ao passo que mantinham o núcleo de suas identidades herdadas, e também contribuíam para uma iniciativa cultural imperial centralizadora" (HINGLEY, 2010, p. 78). 
completamente passiva, a cultura imperial. Aprender o latim não fazia deles romanos, mas era uma maneira de manter a própria cultura, criar e armar mecanismos de defesa.

Como apresentado por Andrew Wallace-Hadrill (2008), a influência da elite romana passa a ser mais dialogada do que imposta, ao passo que novas elites surgem com a expansão territorial e a elevação de algumas províncias. Inúmeras imagens do Imperador eram divulgadas nas províncias - estátuas, moedas, etc. - e cada uma as recebia e incorporava, a partir de suas necessidades, de uma forma singular. A elite provincial se utilizava das imagens do princeps não apenas para estabelecer uma ligação entre ambos, mas também para se posicionarem como superiores perante o restante da população provincial. Nas moedas, como exemplo, Augusto faz questão de divulgar seu signo, Capricórnio, tão elevado e legitimado como o que brilha para os grandes líderes (já citado acima).

\section{Conclusão}

Percebemos que todo um jogo foi elaborado pelos Imperadores (sendo Augusto o exemplo central), Senado e províncias. Não apenas um desses detinha o poder, mas se moldavam, se ligavam e se repeliam a partir de interações pertinentes ao interesse de cada um (indivíduo ou grupo). Entendemos que o Princeps desempenhava o papel de protagonista em toda essa trama, porém, entendemos também que o cenário, as alegorias e os personagens secundários poderiam desempenhar papéis de grande importância. Um jogo era estipulado e muitos jogavam, ao tentarem se manter próximos da irradiação que o poder imanava. Augusto em seus atos solenes como restaurador da República, nada mais foi que um excelente jogador, pois soube concluir sua estratégia, sendo reconhecido por inúmeros autores (Veléio Patérculo, Suetônio, Plutarco...) como um exemplo de bom líder. O Senado, que se "deixava ludibriar", sabia o momento de contra-atacar e posicionar-se em favor de seus próprios interesses, mesmo perante o Imperador. Enquanto isso, povo e províncias (nos utilizando desses termos generalizantes), mesmo que distantes, também se arriscavam nessa modulação intensa de poder. Os astros, através das leis secretas e do destino que salvaguardam, já determinavam os acontecimentos terrenos: mesmo que esses superassem as expectativas humanas. Mas quem melhor, assim como aponta Marco Manílio, para compreender todo o Universo do que aqueles que dele foram criados? Entender o Universo seria entender o mundo terreno e, também, confirmar o poder dos poderosos. 


\title{
THE ASTRAL ORDER: THE PRINCEPS OCTAVIUS AUGUSTUS' ACTION FOR HIS POWER LEGITIMACY
}

\begin{abstract}
We look back for political relationships during Roman Empire, searching for understand ours presents experiences. Taking this action, we realize that roman leaders already articulated theirs ideas in face of a big and heterogeneous crowd. In that way, propagate a good image was not a necessity only for the princeps (or actual): Senate, people of Rome and provinces needed to adopt specific postures to get, also, benefits. Games of power were established and for understand theses, we analyze Octavius Augustus government. We analyze this period, because represents a rupture between two moments of Roman History (Republic and Empire), at the same time that this leader realize, when we consider his postures and speeches, a continuity of traditional republican elements. In other words, his speech was produced to confirm his actions, and to convince everyone of his legitimacy. Searching for order, Marcus Manilius, Astronomicas' author, provided new tools for this work; even the stars explains the different powers of Octavius, Senate and roman people.

Key-words: Propaganda - Power - Astrology - Octavius Augustus.
\end{abstract}

\section{Bibliografia}

\section{Documentos Textuais:}

MARCUS MANILIUS. Astrologia. Introdução de Francisco Calero e Tradução de Francisco Calero e Maria José Echarte. Madrid: Editorial Gredos, 1996.

MARCUS MANILIUS. Astronômicas - tradução, introdução e notas. Trad. Marcelo Vieira Fernandes. São Paulo: USP, 2006.

MARCUS MANILIUS. Astronomicas. Trad. G. P. Goold. Cambridge: Harvard University Press/ London: Heinemann, 1977. (Loeb Classical Library).

FERNANDES, Marcelo Vieira. Manílio Astronômicas - tradução, introdução e notas. São Paulo: USP, 2006.

PLUTARCH. "The Life of Antony". In: PLUTARCH. The Parallel Lives. Trad. Bernadotte Perrin. London: William Heinemann, 1919. (The Loeb Classical Library). RES GESTAE DIVI AUGUSTI. Trad. Frederick W. Shipley. London: Harvard University Press, 1961. (The Loeb Classical Library).

SUETÔNIO. A Vida dos Doze Césares. London: William Heinemann, 1914. (The Loeb Classical Library)

VELEYO PATÉRCULO. Historia Romana. Trad. Maria Assunción Sánchez Manzano. Madrid: Ed. Gredos, 2001.

Historiografia:

ANDO, Clifford. Consensus in Theory and Pratice. In: Imperial Ideology and Porvincial Loyalty in the Roman Empire. California: University of California Press, 2000, p. 131-174.

GONGALVES, Ana Teresa M. Astrologia e poder $\neq$ o caso de Marcus Manilius. São Leopoldo: ANPUH, 2007. 
- A construção da imagem imperial: formas de propaganda nos governos de Septímio Severo e Caracala. São Paulo: USP, 2002.

. Honra e Poder: o discurso de Marco Antônio após o assassinato de Júlio César na obra de Dion Cássio. In: Literatura, Poder e Imaginários Sociais no Mediterrâneo Antigo. Goiânia: Editora da PUC Goiás, 2010, p. 101-112.

HINGLEY, Richard. Diversidade e Unidade culturais: Império e Roma, In:

O Imperialismo romano: novas perspectivas a partir da Bretanha. São Paulo: Annablume, 2010, p. 67-93.

HUSKINSON, Janet. Looking for culture, identity and Power. In:

(ed.). Experiencing Rome: Culture, identity and Power in the Roman Empire. London: Routledge, 2005, p. 3-27.

LENDON, J. E.. Honour and influence in the Roman Word. In: Empire of Honour. The Art of government in the Roman Word. New York: Oxford Press, 2005, p. 30-106.

LOBUR, John Alexandre. Consensus, Concordia, and the Formation of Roman Imperial Ideology+ Studies in Classics. New York/London: Routledge, 2008.

MILES, Richard. Communicating culture, identity and Power. In: HUSKINSON, Janet. Experiencing Rome: Culture, identity and Power in the Roman Empire. London: Routledge, 2005, p. 29-62.

REVELL, Louise. The Roman Emperor, In: Roman Imperialism and local indentities. Cambridge University Press, p. 80-109.

SUMI, Geoffrey S.. The Princeps as Performer. In: Ceremony and Power. Performing Politics in Rome between Republic and Empire. Michigan: University of Michigan Press, 2005, p. 220-262.

VEYNE, Paul. O que era um imperador romano. In: O Império Greco-romano. Rio de Janeiro: Elsevier, 2009, p. 1-34.

WALLACE-HADRILL, Andrew. Culture, identity and power. In: Rome's Cultural Revolutio. Cambridge: Cambridge University Press, 2008, p. 3-36. 